\title{
Tocophobia: overwhelming fear of pregnancy and childbirth
}

\author{
Jissa Donel* \\ Nursing Tutor, College of Nursing, All India Institute of Medical Sciences (AIIMS), Raipur, Chhattisgarh, India
}

Received: 12 August 2019

Accepted: 04 October 2019

\section{*Correspondence:}

Jissa Donel,

E-mail: doneljis@gmail.com

Copyright: $\odot$ the author(s), publisher and licensee Medip Academy. This is an open-access article distributed under the terms of the Creative Commons Attribution Non-Commercial License, which permits unrestricted non-commercial use, distribution, and reproduction in any medium, provided the original work is properly cited.

\begin{abstract}
Pregnancy and childbirth are a major life process for women. Childbirth is an outstanding life event for every woman. It is considered as normal to experience concern or anxiety to a certain degree, as it can help women to make ready for childbirth. But, if the fear becomes paralyzing and terrifying, it can turn out to be physically and emotionally disabling and give rise to a specific pathology termed as tocophobia. The aim of the present article is to analyze the tocophobic condition and to give a brief overview of the possible approaches currently available to mitigate the tocophobic condition.
\end{abstract}

Keywords: Anxiety, Fear of childbirth, Pregnancy, Tocophobia

\section{INTRODUCTION}

Nearly $80 \%$ of pregnant women express worries and fears in relation to their pregnancy or upcoming childbirth. ${ }^{1}$ Literature estimates that one in five pregnant women experience moderate fear of childbirth and 6-10\% of all pregnant women suffer from a severe fear of childbirth (FOC) worldwide..$^{2-4}$ Prevalence rates ranges between 3.7 and $43 \%$. The prevalence of tocophobia is estimated at $14 \%$ and appears to have increased in recent years. ${ }^{5}$

FOC is usually not a pathological fear, but a situational fear which is personal to the individual. Fear of childbirth is commonly framed as a phenomenon within the domain of anxiety. ${ }^{6}$ This fear exists on a spectrum from low fear to high and phobic fear but it is difficult to assess when fear of childbirth becomes 'to-cophobia'.

When the specific anxiety or fear of death during parturition precedes pregnancy and is so intense that tokos (childbirth) is avoided whenever possible, leads to the phobic state called "tocophobia." Tocophobia is defined as "an unreasoning dread of childbirth,". 7 It is synonymous to the terminologies: maleusiophobia and parturiphobia. Tokophobia as an obsessive fear of childbirth was recognized as a specific medicalpsychological phobia only with the study of Hofberg and Brockinton in the year 2000 .

\section{Classification}

Classified into primary (affecting nulliparous women) and secondary (affecting parous women usually after a previous birth experience) ${ }^{8}$

\section{Primary tocophobia}

When dread of childbirth predates the first conception, this is primary tocophobia. The dread of childbirth may start in adolescence or early adulthood. Although sexual relations may be normal, contraceptive use is often scrupulous. Pregnancy is avoided to prevent parturition. In some tragic cases, a woman is so terrified of childbirth she will terminate a wanted pregnancy rather than go through childbirth. ${ }^{7}$

\section{Secondary tocophobia}

Some women develop a dread and avoidance of childbirth after delivery. Most typically, this is a 
"traumatic" delivery, but it could also occur after an obstetrically normal delivery, a miscarriage, a stillbirth, or a termination of pregnancy. The fear may be manifested either as a wish to have a CS or to avoid the current pregnancy and childbirth. ${ }^{8}$

\section{Tocophobia as a symptom of depression}

When a woman (regardless whether she had a previous pregnancy or not) has co-existing depression and recurrent intrusive thoughts that she would die if she tries to deliver the baby.

\section{Etiological considerations for tocophobia}

The etiology of tocophobia is multifaceted and complex. It is often associated with various sociodemographic and psychosocial characteristics. History of sexual abuse, traumatic experience in prior deliveries, previous miscarriages, long duration of infertility, smoking, low social support system, poor partner relationships, partner violence, unintended pregnancy, lack of trust in or worries about unfriendly staff, being left alone in labor, lack of involvement in decision-making etc are certain reasons for the development of tocophobia. ${ }^{4}$ Qualitative evidence suggests that FOC may be transmitted from generation to generation through vicarious experiences of family members who had difficult labours or negative births. In addition, FOC often coincides with depressive and compulsive personalities predisposing women to postnatal depression and post-traumatic stress disorder.

\section{Diagnosis of tocophobia}

FOC can be assessed using a range of self-reported questionnaires or diagnostic interviews. While there are no standard criteria for defining tocophobia, the Wijma Delivery Expectancy Questionnaire Part A (W-DEQ A) is the most commonly used tool for assessment and diagnosis. ${ }^{9}$

\section{What's the fear about??}

Various studies have investigated the causes of tocophobia. Typical sources of fear include fear of the unknown, fear of pain, fear of perineal trauma, feeling lack of involvement in decision-making during birth, being left alone in labour, fear for the infant's health or own health or death. ${ }^{10,11}$

Data from more than 8000 expectant mothers (collated via a prenatal questionnaire distributed between November 1, 1991 and October 31, 1999) are evaluated. The most frequent fears mentioned are fear for the child's health $(50 \%)$ and fear of pain $(40 \%)$. Fears dealing with medical intervention, such as operative delivery, anesthesia, nerve blockage and of being at the mercy of obstetrics all lie at around $12 \% .^{12}$

\section{Consequences of tocophobia}

FOC exists on a spectrum from minor worries and anxieties, to moderate FOC which does not impact women's everyday life, to severe FOC (tocophobia), which has a considerable impact on women's lives and affects their psychological well-being. ${ }^{13-15}$

For some women, FOC is so severe that it affects their daily lives, and spoils their experience of pregnancy. ${ }^{10} \mathrm{In}$ extreme cases, women use scrupulous methods of contraception to avoid pregnancy, experience psychosexual difficulty, may choose to terminate a healthy pregnancy, conceal or be in denial about pregnancy.

Tocophobia complicates pregnancy and causes manifestations of anxiety and stress leading to physical and psychological disorders including hypertension, preeclampsia, poor postpartum mental health and posttraumatic stress disorder. ${ }^{16-18}$ These complications would result in increased probability of obstetric interventions particularly emergency caesarean section that in turns, may lead to low birth weight and preterm labour. ${ }^{19,20} \mathrm{~A}$ positive association has been found between level of childbirth fear and the tendency to wish for, or request a Caesarean section. Physical and psychological effects such as sleeplessness, nightmares, stomachaches, depression and anxiety leading to panic attacks haven been reported. ${ }^{21,22}$ High levels of maternal stress during pregnancy can double the probability of emotional or behavioural problems in childhood.

\section{Measures to tackle tocophobia}

Over the last 30 years, there has been increasing interest in tocophobia, both in empirical research and clinical practice. Providing appropriate care for pregnant women with high or severe fear of childbirth (FOC) is a challenge in midwifery care today. There is no standardized care pathway for women with tocophobia in pregnancy. It is therefore important to establish which interventions may increase a woman's faith in her own ability to cope with labour and birth.

Improved perinatal and psychological support in maternity services is much needed to tackle the issue. Interventions that target psychosocial factors using a combination of various approaches promote a reduction in fear and provide a positive birth experience. Providing a sense of security and safety is particularly important for women with FOC throughout the antenatal period. Approaches that focuses on understanding the birth process and awareness of the body in general also helps in preparing the mother emotionally ready for childbirth. ${ }^{23}$ Providing pregnant women with a trusting relationship could also help to reduce the fear. ${ }^{24}$ Psychoeducation, hypnosis, cognitive behaviour therapy, roleplay education, telephonic counseling sessions, yoga classes, relaxation training programmes etc were 
considered as certain types of interventions that are effective in reducing the fear related to childbirth.

\section{DISCUSSION}

\section{Discussion on interventions for reducing tocophobia}

Several RCTs and quazi randomized control trials were conducted in different countries across the world in exploring and comparing various interventions for the treatment of fear of childbirth.

Psycho-education by trained midwives was found effective in reducing high childbirth fear levels and increasing childbirth confidence in pregnant women. Antenatal education classes largely focus on teaching about pregnancy, childbirth processes and labour, midwifery and nursing practices during labor and also familiarizes the antenatal women about the birthing suite. Providing these information helps to change the attitudes and believes of pregnant women toward pregnancy and childbearing and leads to a positive perception of labour and consequently brings about positive experiences related to childbirth. Three studies were carried out in Turkey which evaluated the effectiveness of antenatal education in reducing tocophobia. One study was an RCT and other two studies followed quazi experimental design. Kızılırmak and Başer reported that a 70 minutes preparatory labour education performed on primi-gravida women in two sessions at the third trimester was significantly effective in decreasing fear of birth. Similar to this, Serçekuş and Başkale provided an antenatal class education in third trimester of pregnancy and participants in the intervention group presented significantly lower W-DEQ- A mean score. All three studies reported that antenatal education significantly reduced the fear of childbirth of expectant mothers. ${ }^{25-27}$ Toohil $\mathrm{J}$ conducted an RCT in Australia in 2014, in which the intervention tried was a telephonic psycho education counselling to pregnant women at 36 weeks of gestation. As compared to previously mentioned studies, this study also reported a reduction in fear related to childbirth due to the effect of the intervention. ${ }^{28}$ Another study conducted among 371 Swedish nulliparous women with severe fear of childbirth, by Rouhe et al. Study revealed a significant effect of group psycho-education classes and relaxation exercise during pregnancy on experience of childbirth in 3 months of postpartum among women suffering from severe fear. ${ }^{29}$ Another single-arm pilot study tested the effect of a mindfulness-based childbirth education as a new model of childbirth education. This model consisted of mindfulness, communication and decision-making skills and showed to be a significant effective intervention for reducing FOC. ${ }^{30}$ A systematic review and meta-analysis of clinical trials related to the interventions for reducing the fear of childbirth gave ample evidences related to the efficacy of psychoeducation. ${ }^{31}$

Cognitive behaviour therapy which focus on psychological factors is found to be helpful in preparing women for birth and transition to motherhood. ${ }^{25} \mathrm{CBT}$ has demonstrated an improvement in symptoms of FOC in this population as well as decreased CS on request. ${ }^{13,19} \mathrm{~A}$ systematic literature search performed by Cochrane Collaboration gave the evidence that cognitive therapy sessions are effective interventions in reducing tocophobia. ${ }^{32}$

Self-hypnosis relieves pain and decrease the demand for chemical pain relief through stimulating the release of the endorphins as natural painkillers and suppression of neural activity to inhibit the emotional interpretation of sensations such as pain. In a randomized controlled trial (RCT) conducted by Werner et al, among 1222 healthy Danish nulliparous women, a brief course of selfhypnosis significantly ameliorated FOC experienced during 6 weeks after birth while relaxation techniques did not have any significant influence on FOC. ${ }^{33}$

Antenatal yoga courses brought a significant reduction in fear of childbirth in an RCT conducted by Newham JJ et al, in $2014 .^{34}$

Patients with FOC are prone to catastrophise pain in labour and birth, leading to more intense perceived pain, therefore they may be more likely to utilise epidural analgesia during labour. ${ }^{31}$ In a study by Adams and colleagues, women with FOC were significantly more likely to request an epidural than women without FOC. ${ }^{35}$ More recently, a study by Logtenberg and colleagues, also found that women with FOC were more likely to request pharmacological pain relief but it was not statistically significant. ${ }^{36}$

\section{CONCLUSION}

Despite being initially documented in the medical literature over 150 years ago, tocophobia still remains largely unrecognized within the obstetric community as well as the wider health profession. During the past decade, however, interest in fear of childbirth has expanded.

Assisting women to achieve a normal birth will improve women's quality of reproductive life, reduce health care costs, and improve postpartum maternal and child health outcomes. Asking women explicitly about their fears and concerns will significantly lower the fear and enhance the childbirth confidence. Empirical knowledge about these aspects would be of great benefit in understanding the phenomenon of childbirth-related fear, and in developing interventions that might be helpful for the large number of women experiencing anxiety of this kind.

Tocophobia could be a very debilitating condition but with good supportive multidisciplinary care, an excellent outcome is possible.

Funding: No funding sources

Conflict of interest: None declared 
Ethical approval: Not required

\section{REFERENCES}

1. Melender HL. Experiences of fears associated with pregnancy andchildbirth: A study of 329 pregnant women. Birth: Issues in Perinatal Care; 2002:29(2):101-11.

2. Hanna-Leena Melender R. Experiences of fears associated with pregnancy and childbirth: a study of 329 pregnant women. Birth. 2002;29(2):101-11.

3. Poikkeus P, Saisto T, Unkila-Kallio L, Punamaki RL, Repokari L, Vilska S, et al. Fear of childbirth and pregnancy-related anxiety in women conceiving with assisted reproduction. Obstet Gynecol. 2006;108(1):70-6.

4. Rouhe H, Salmela-Aro K, Halmesmaki E, Saisto T. Fear of childbirth according to parity: gestational age, and obstetric history. BJOG. 2009;116(1):67-73.

5. O'connell MA, Leahy-Warren P, Khashan AS, Kenny LC, O'neill SM. Worldwide prevalence of tocophobia in pregnant women: systematic review and meta-analysis. Acta Obstetr Gynecol Scandinavica. 2017;96(8):907-20.

6. Huizink AC, Mulder EJH, de Medina PGR, Visser, GHA, Buitelaar JK. Is pregnancy anxiety a distinctive syndrome? Early Human Develop. 2004;79(2):81-91.

7. Hofberg KM, Brockington IF. Tokophobia:an unreasoning dread of childbirth. A series of 26 cases. Br J Psychiatry. 2000;176:83-5.

8. Hofberg, K, Ward M. Tokophobia: A profound dread and avoidance of childbirth (when pathological fear effects the consultation). In: J Cockburn, and ME Pawson (Eds.), Psychological challenges in obstetrics and gynecology: The clinical management. New York, NY: Springer Science + Business Media. 165-172.

9. Wijma K, Wijma B, Zar M. Psychometric aspects of the WDEQ; a new questionnaire for the measurement of fear of childbirth. Journal of Psychosomatic Obstet Gynecol. 1998;19(2):84-97.

10. Salomonsson B, Wijma K, Alehagen S. Swedish midwives'perceptions of fear of childbirth. Midwifery. 2010;26(3):327-37.

11. Fenwick J, Toohill J, Creedy DK, Smith J, Gamble J. Sources, responses and moderators of childbirth fear in Australian women: a qualitative investigation. Midwifery. 2015;31(1):239-46.

12. Geissbuehler V, Eberhard J. Fear of childbirth during pregnancy: a study of more than 8000 pregnant women. J Psychos Obstet Gynecology. 2002;23(4):229-35.

13. Larsson B, Hildingsson I, Ternström E, Rubertsson C, Karlström A. Women's experience of midwife-led counselling and its influence on childbirth fear: A qualitative study. Women and Birth. 2018;2(1):e88e94.

14. Nilsson C, Hessman E, Sjöblom H, Dencker A, Jangsten E, Mollberg $\mathrm{M}$, et al. Definitions, measurements and prevalence of fear of childbirth: a systematic review. BMC Pregn Childbirth. 2018;18(1):28

15. Glover V. The effects of prenatal stress on child behavioural and cognitive outcomes start at the beginning. Encycl Early Child Dev. 2011:1-5.

16. Rouhe H, Salmela-Aro K, Gissler M, Halmesmaki E, Saisto T. Mental health problems common in women with fear of childbirth. BJOG. 2011;118(9):1104-11.

17. Chung TK, Lau TK, Yip AS, Chiu HF, Lee DT. Antepartum depressive symptomatology is associated with adverse obstetric and neonatal outcomes. Psychosom Med. 2001;63(5):830-4.

18. Kurki T, Hiilesmaa V, Raitasalo R, Mattila $\mathrm{H}$, Ylikorkala O. Depression andanxiety in early pregnancy and risk for preeclampsia. Obstet Gynecol. 2000;95(4):487-90.

19. Saisto T, Halmesmäki E. Fear of childbirth can be treated, and cesarean section on maternal request avoided. Acta Obstet Gynecol Scand. 2007;86(9):1148-9.

20. Størksen HT, Garthus-Niegel S, Adams SS, Vangen S, Eberhard-Gran M. Fear of childbirth and elective caesarean section: a population-based study. BMC Preg Childbirth. 2015;15(1):1.

21. Laursen M, Hedegaard M, Johansen C. Fear of childbirth: predictors and temporal changes among nulliparous women in the Danish National Birth Cohort. BJOG: Int J Obstet Gynaecol. 2008;115(3):354-60.

22. Räisänen S, Lehto SM, Nielsen HS, Gissler M, Kramer MR, Heinonen S. Fear of childbirth in nulliparous and multiparous women: a populationbased analysis of all singleton births in Finland in 1997-2010. BJOG: Int J Obstet Gynaecol. 2014;121(8):965-70.

23. Airo Toivanen R, Korja R, Saisto $\mathrm{T}$, Rouhe $\mathrm{H}$, Muotka J, Salmela-Aro K. Changes in emotions and personal goals inprimiparous pregnant women during group intervention for fear of childbirth. J Repro Infant Psychol. 2018;36(4):363-80.

24. Hildingsson I, Rubertsson C, Karlström A, Haines H. Caseload midwifery for women with fear of birth is a feasible option. Sexual Reprod Healthcare. 2018;1(16):50-5.

25. Kızılırmak A, Başer $M$. The effect of education given to primigravida women on fear of childbirth. Appl Nurs Res. 2016;29:19-24.

26. Karabulut Ö, Coşkuner Potur D, Dog an Merih Y, Cebeci Mutlu S, Demirci N. Does antenatal education reduce fear of childbirth? Int Nurs Rev. 2016;63(1):60-7.

27. Serçekuş P, Başkale H. Effects of antenatal education on fear of childbirth, maternal self-efficacy and parental attachment. Midwifery. 2016;34:16672.

28. Toohill J, Fenwick J, Gamble J, Creedy DK, Buist A, Turkstra E, Ryding EL. A randomized controlled trial of a psycho-education intervention by midwives 
in reducing childbirth fear in pregnant women. Birth. 2014;41(4):384-94.

29. Rouhe H, Salmela-Aro K, Toivanen R, Tokola M, Halmesmäki E, Ryding E, et al. Group psychoeducation with relaxation for severe fear of childbirth improves maternal adjustment and childbirth experience: a randomised controlled trial. J Psychosom Obstet Gynecol. 2015;36(1):1-9.

30. Byrne J, Hauck Y, Fisher C, Bayes S, Schutze R. Effectiveness of a mind fulness based childbirth education pilot study on maternal self-efficacy and fear of childbirth. J Midwifery Womens Health. 2014;59(2):192-7.

31. Hosseini VM, Nazarzadeh M, Jahanfar S. Interventions for reducing fear of childbirth: A systematic review and meta-analysis of clinical trials. Women Birth. 2018;31(4):254-62.

32. O'Connell MA, O'Neill SM, Dempsey E, Khashan AS, Leahy-Warren P, Smyth RM, et al. Interventions for fear of childbirth (tocophobia). Cochrane Database Systematic Reviews. 2019:5.

33. Werner A, Uldbjerg N, Zachariae R, Wu CS, Nohr EA. Antenatal hypnosis training and childbirth experience: a randomized controlled trial. Birth. 2013;40(4):272-80.

34. Newham JJ, Wittkowski A, Hurley J, Aplin JD, Westwood M. Effects of antenatal yoga on maternal anxiety and depression: a randomized controlled trial. Depress Anxiety. 2014;31(8):631.

35. Adams SS, Eberhard-Gran M, Eskild A. Fear of childbirthand duration of labour: a study of 2206 women withintended vaginal delivery. BJOG: Int J Obstet Gynaecol. 2012;119(10):1238-46.

36. Logtenberg SL, Verhoeven CJ, Rengerink KO, Sluijs AM, Freeman LM, Schellevis FG, et al. Pharmacological pain relief and fear of childbirth in low risk women; secondary analysis of the RAVEL study. BMC Preg Childbirth. 2018;18(1):347.

Cite this article as: Donel J. Tocophobia: overwhelming fear of pregnancy and childbirth. Int J Reprod Contracept Obstet Gynecol 2019;8:4641-5. 